\title{
Comparison of commercial DNA preparation kits for the detection of Brucellae in tissue using quantitative real-time PCR
}

\author{
Herbert Tomaso*1,2, Mireille Kattar³, Meike Eickhoff4, Ulrich Wernery5, Sascha Al Dahouk6, Eberhard Straube7, \\ Heinrich Neubauer ${ }^{1}$ and Holger C Scholz ${ }^{2}$
}

\begin{abstract}
Background: The detection of Brucellae in tissue specimens using PCR assays is difficult because the amount of bacteria is usually low. Therefore, optimised DNA extraction methods are critical. The aim of this study was to assess the performance of commercial kits for the extraction of Brucella DNA.

Methods: Five kits were evaluated using clinical specimens: QIAamp ${ }^{\text {TM }}$ DNA Mini Kit (QIAGEN), peqGold ${ }^{\text {TM }}$ Tissue DNA Mini Kit (PeqLab), UltraClean ${ }^{\text {TM }}$ Tissue and Cells DNA Isolation Kit (MoBio), DNA Isolation Kit for Cells and Tissues (Roche), and NucleoSpin ${ }^{\text {TM }}$ Tissue (Macherey-Nagel). DNA yield was determined using a quantitative real-time PCR assay targeting IS711 that included an internal amplification control.

Results: Kits of QIAGEN and Roche provided the highest amount of DNA, Macherey-Nagel and Peqlab products were intermediate whereas MoBio yielded the lowest amount of DNA. Differences were significant $(p<0.05)$ and of diagnostic relevance. Sample volume, elution volume, and processing time were also compared.

Conclusions: We observed differences in DNA yield as high as two orders of magnitude for some samples between the best and the worst DNA extraction kits and inhibition was observed occasionally. This indicates that DNA purification may be more relevant than expected when the amount of DNA in tissue is very low.
\end{abstract}

\section{Background}

Brucellosis is a 're-emerging' zoonosis with a worldwide distribution caused by small fastidious Gram negative bacteria of the genus Brucella. Patients present with nonspecific signs and symptoms such as inconstant fevers, sweating, weakness, headaches, depression, weight loss, and muscle and body pain. The disease can become chronic with focal lesions which can affect various organs. The cultivation and identification of Brucella species with conventional microbiological techniques is time-consuming and hazardous and should be performed under BSL-3 conditions [1]. Real-time PCR assays allow for the rapid and specific detection of Brucella species, but the amount of bacteria in tissues and body fluids is frequently extremely low $[2,3]$. Therefore, DNA extrac-

\footnotetext{
* Correspondence: herbert.tomaso@web.de

1 Friedrich-Loeffler-Institut, Institute of Bacterial Infections and Zoonoses, Naumburgerstrasse 96a, 07743 Jena, Germany

Full list of author information is available at the end of the article
}

tion is a critical step to avoid false negative PCR results. In general, blood and serum are regarded as valuable specimens, but biopsies of focal lesions are more relevant in chronic courses of the disease [4-6]. The material obtained with biopsies is usually scarce and can contain inhibitory components that make PCR diagnosis even more difficult. The performance of commercial kits for the preparation of DNA from serum has been evaluated by Queipo-Ortuno et al. [7], but no systematic study has been performed using clinical tissue specimens. Therefore, the aim of this study was to compare the performance of commercially available kits for the extraction of Brucella DNA from infected tissues.

\section{Methods}

Samples and tissue homogenization

Organ samples were obtained from two dromedaries from Dubai, United Arab Emirates (UAE), which were serological positive for brucellosis and had to be 
destroyed by UAE law (Ministerial degree of the UAE no. 132/2004). Both dromedaries were euthanized with T61 and samples were obtained from different organs (Tab. 1) for the isolation of Brucella organisms as described previously [8]. Culture proved generalized Brucella melitensis infections in both animals. Identification of the pathogen was performed using conventional microbiological techniques including species-specific AMOS PCR [9]. Six tissue samples of each animal were used to assess the performance of commercial DNA extraction kits. Initially, pieces of tissue $(\sim 5 \mathrm{~g})$ were inactivated and preserved in formalin $(10 \% \mathrm{v} / \mathrm{v})$. Subsequently the specimens were washed twice in deionized water $(10 \mathrm{ml})$, and incubated over night in $20 \mathrm{ml}$ sterile physiological saline at $4^{\circ} \mathrm{C}$. DNA extraction was done as described previously [10]. In brief, the specimens were cut into small pieces $(\sim 150 \mathrm{mg})$ and made up with PBS to $1 \mathrm{ml}$ in a sampler tube. The tubes were shaken in a FastPrep-24 Instrument (MP Biomedicals, Illkirch, France) at speed 5.0 for $20 \mathrm{~s}$ according to the manufacturer's instructions and placed on ice for further $20 \mathrm{~s}$. This procedure was repeated five times. The sampler tubes were then centrifuged at 14.000 $\mathrm{rpm}$ for $20 \mathrm{~min}$ at $4^{\circ} \mathrm{C}$. DNA was prepared from $50 \mu \mathrm{l}$ aliquots of the supernatant.

\section{DNA purification methods}

The five commercial kits used in this study are briefly described below along with the modifications introduced in each case to the manufacturer's instructions:
UltraClean ${ }^{\text {tw }}$ Tissue and Cells DNA Isolation Kit (MoBio): The protocol was followed to step 9. The elution (steps 10 to 12) was done using $100 \mu \mathrm{l}$ TD3 buffer instead of $50 \mu \mathrm{l}$.

PeqGold ${ }^{\mathrm{m}}$ Tissue DNA Mini Kit (PeqLab): The protocol was followed from step 1 to step 7 . Only the optional step 2 (RNase digestion) was not included. Elution was done using $100 \mu \mathrm{l}$ elution buffer instead of $200 \mu \mathrm{l}$.

QIAampDNA ${ }^{\mathrm{m}}$ Mini Kit (QIAGEN): The protocol for tissue samples was followed including procedure 3a (without RNase treatment described in $3 \mathrm{~b}$ ) to step 8, but elution was done using $100 \mu \mathrm{l}$ elution buffer.

DNA Isolation Kit for Cells and Tissues (Roche): The procedure for DNA isolation from $100 \mathrm{mg}$ - $1 \mathrm{~g}$ tissue was followed as recommended by the manufacturer.

NucleoSpin ${ }^{\mathrm{Tm}}$ Tissue (Macherey-Nagel): The protocol for genomic DNA purification from tissue was used as described by the manufacturer.

\section{Real-time PCR}

The amount of DNA was determined in triplicates using a real-time PCR assay with hybridization probes targeting the insertion sequence IS711, which is present in 6-7 copies per genome in Brucella abortus, melitensis, and suis. An internal amplification control targeting bacteriophage lambda DNA was included to determine inhibitory effects of the sample matrix as described previously [11]. Primers and probes were designed based on alignment studies using the BLAST program and the sequence data-

Table 1: Mean concentration of Brucella melitensis DNA obtained with five purification kits from tissue samples of two dromedaries.

\begin{tabular}{|c|c|c|c|c|c|c|c|c|c|c|}
\hline \multirow[b]{2}{*}{$f g / \mu l$} & \multicolumn{2}{|c|}{ QIAGEN } & \multicolumn{2}{|c|}{ Peqlab } & \multicolumn{2}{|c|}{ Macherey-Nagel } & \multicolumn{2}{|c|}{ MoBio } & \multicolumn{2}{|c|}{ Roche } \\
\hline & mean & SD & mean & SD & mean & SD & mean & SD & mean & SD \\
\hline \multicolumn{11}{|l|}{ D1452/06 } \\
\hline Liver & 8915 & 15150 & 186 & 17 & 76 & 9 & neg & & 207 & 26 \\
\hline Spleen & 10 & 2 & 5 & 2 & 101 & 21 & neg* $^{*}$ & & 402 & 20 \\
\hline Lung & 225 & 66 & 72 & 11 & 216 & 55 & 71 & 23 & 2252 & 89 \\
\hline Right kidney & 1377 & 19 & 73 & 27 & 315 & 24 & 101 & 19 & 757 & 53 \\
\hline Prescapular Ln & 415 & 65 & 111 & 13 & 41 & 11 & 123 & 20 & 1338 & 355 \\
\hline Intestine & 223 & 56 & 90 & 8 & 179 & 29 & neg* $^{*}$ & & 382 & 54 \\
\hline \multicolumn{11}{|l|}{ D1469/06 } \\
\hline Spleen & 484 & 426 & 57 & 4 & 38 & 7 & neg* $^{*}$ & & 67 & 67 \\
\hline Right kidney & 235 & 23 & 10 & 8 & 14 & 3 & 3 & 3 & 111 & 29 \\
\hline Spinal Cord & 289 & 64 & 11 & 1 & 126 & 33 & neg* & & $14^{*}$ & 12 \\
\hline Pancreas & 229 & 57 & 61 & 10 & 179 & 34 & 75 & 15 & $88^{*}$ & 14 \\
\hline Aorta lymph node & 208 & 42 & 4 & 2 & 238 & 41 & neg & & 112 & 11 \\
\hline Mammary Ln & 355 & 299 & 140 & 26 & 297 & 12 & 465 & 60 & 112 & 18 \\
\hline
\end{tabular}

(Ln, lymph node; SD, standard deviation; neg, negative Brucella PCR assay; ${ }^{*}$, negative inhibition control). 
base of the National Centre for Biotechnology Information. The oligonucleotides used for the Brucella specific target were IS711_S TTGTCGATGCTATCGGCCTAC, IS711_R GGCAATGAAGGCCCTTAAGT, IS711_FL GAAGCTTGCGGACAGTCACCATAAT-fluorescein, and IS711_LC LightCycler-Red-640-GCCGGGTGTTGGCTTTATTCG-phosphate. The oligonucleotides used for the detection of the internal amplification control were: Lambda_F ATGCCACGTAAGCGAAACA, Lambda_R GCATAAACGAAGCAGTCGAGT, Lambda_ FL.ss CACTTCCCGAATAAC-fluorescein, and Lambda LC LightCycler-Red-705-CGGATATTTTTGATCTGAC CGAAGCG-phosphate. Primers and probes were obtained from and designed in cooperation with TIB MOLBIOL (Berlin, Germany). A real-time hot-start PCR was performed with the LightCycler FastStart DNA Master Hybridisation Probes Kit ${ }^{\mathrm{mw}}$ (Roche Diagnostics, Mannheim, Germany) in a LightCycler Instrument ${ }^{\text {tim }}$ (Roche Diagnostics, Mannheim, Germany). The $20 \mu \mathrm{l}$ reaction mixture contained $3 \mathrm{mM} \mathrm{MgCl}, 2 \mu \mathrm{l} 10 \times$ LightCyclerFastStart Reaction Mix Hybridisation Probes, $0.5 \mu \mathrm{l}$ of each primer $\left(20 \mathrm{pmol}^{-1} \mathrm{l}^{-1}\right), 0.5 \mu \mathrm{l}$ of each hybridisation probe $\left(8 \mathrm{pmol}^{\mathrm{l}} \mathrm{l}^{-1}\right)$ and $2 \mu \mathrm{l}$ template. No-template controls that contained $2 \mu \mathrm{l}$ of PCR water instead of DNA and positive controls that contained DNA of Brucella melitensis were included in each run to detect any amplicon contamination or amplification failure. Reaction conditions were: $10 \mathrm{~min}$ at $95^{\circ} \mathrm{C}, 45$ cycles of $10 \mathrm{~s}$ at $95^{\circ} \mathrm{C}, 10 \mathrm{~s}$ at $55^{\circ} \mathrm{C}$ and $15 \mathrm{~s}$ at $72^{\circ} \mathrm{C}$. A melting curve analysis was performed after the last amplification cycle with $95^{\circ} \mathrm{C}$ for $0 \mathrm{~s}, 45^{\circ} \mathrm{C}$ for $30 \mathrm{~s}$, and $95^{\circ} \mathrm{C}$ for $0 \mathrm{~s}$. Temperature change rates were $20^{\circ} \mathrm{Cs}^{-1}$ for all but the melting curve analysis, where the rate was $0.1^{\circ} \mathrm{Cs}^{-1}$. Data analyses were performed with LightCycler software version 5.32. The automated second derivative maximum method was used for standardized calculation of the threshold cycle number $\left(C_{T}\right)$. Readout of LightCycler-Red 640 values was performed in channel F2/F1 and readout of LightCycler-Red 705 values was performed in channel F3/F2. Cycle threshold values were used to calculate the amount of DNA that was prepared from the tissue samples. A positive result was assigned when at least two of the triplicate reactions gave a $C_{T}$ value $<40$ and the values were used for further calculations. In order to generate a standard curve for the quantification of Brucella DNA the concentration of purified $B$. melitensis DNA was determined spectrophotometrically using a NanoDrop ND-1000 UVVis spectrophotometer (Nano-Drop Technologies, Wilmington, DE, USA). This quantified DNA was used for serial dilutions with PCR-grade water. Based on the full bacterial genome sequence of $B$. melitensis published in GenBank (accession numbers NC 003317 and NC 003318), it was determined that each Brucella genome copy (i.e., genome equivalent [GE]) amounts to $3.38 \mathrm{fg}$ according to the following equation: $\mathrm{GE}(\mathrm{fg})=$ number of base pairs per GE $\times 618 \mathrm{~g} \mathrm{~mol}^{-1} \times 10^{15} / 6.023 \times$ $10^{23} \mathrm{~mol}^{-1}$ (Avogadro constant).

\section{Statistics}

Statistical analysis was performed using STATISTICA 7.1 (StatSoft Inc., Tulsa, OK 74104, USA) and Microsoft ${ }^{\circ}$ Office Excel 2003 (11.8105.8107) SP2. Significant differences between group values were determined by one-way ANOVA at $\mathrm{p} \leq 0.05$. One-way ANOVA assumes that the variances of the groups are all equal. Therefore a test for homogeneity of variances was performed (Levene test, data not shown). If the significance value exceeds 0.05 , the assumption that the variances are equal is justified. In cases where differences among group means exist, post hoc range tests and pair wise multiple comparisons were performed (data not shown). For one-way ANOVA post hoc tests the Scheffe test was used if equal variances were shown. If equal variances could not be assumed the Dunnett's T3 test was used. A probit analysis to determine the limit of detection was performed using PriProbit 10 version 1.63 designed by Dr. Masayuki Sakuma (Kyoto University, Kyoto, Japan, http://bru.gmprc.ksu.edu/proj/ priprobit/index.asp). The statistical significance was set at a level of $\mathrm{p}=0.05$. The linear range of the insertion sequence IS711-based real-time PCR was determined according to the approved Clinical and Laboratory Standards Institute (CLSI) guidelines for the evaluation of the linearity of quantitative measurement procedures [12]. Seven equally spaced concentrations were analyzed with eight replicates at each level. Based on a polynomial method, two alternative statistical models (linear and nonlinear) were assessed relative to which is most likely to be true (1st-, 2nd- and 3rd- order least-squares regression). When a nonlinear polynomial fits the data better, it was assessed if the difference between the best-fitting nonlinear and linear polynomial is less than the amount of allowable bias for the method. If necessary, corrections (shortening of the linear range) were done and 1st-, 2ndand 3rd- order least-squares regression was conducted again. The linear range was determined, when the linear model fitted best. Based on a generated standard curve (data not shown) the determined $C_{\mathrm{T}}$ values of each sample were converted to quantitative results by using the logarithmic transformed function $y=-1.8573 \operatorname{Ln}(x)+$ 41.18 with $\mathrm{y}=$ generated $\mathrm{C}_{\mathrm{T}}$ value and $\mathrm{x}=$ unknown DNA concentration.

\section{Results}

The detection limit of the real-time PCR assay was 2.35 genome equivalents per PCR reaction with a probability of $95 \%$ as determined using Probit analyses. The linear range was calculated to be 260 to $2.6 \times 10^{7} \mathrm{fg}$ per reaction. 
Table 2: Characteristics of DNA extraction kits.

\begin{tabular}{|c|c|c|c|c|c|}
\hline Company & $\begin{array}{c}\text { MoBio } \\
\text { (Dianova) }\end{array}$ & Roche & QIAGEN & Peqlab & Macherey Nagel \\
\hline Kit & $\begin{array}{l}\text { UltraClean }{ }^{\text {TM }} \text { Tissue and } \\
\text { Cells DNA Isolation Kit }\end{array}$ & $\begin{array}{l}\text { DNA Isolation Kit for } \\
\text { Cells and Tissues }\end{array}$ & QIAamp ${ }^{T M}$ DNA Mini Kit & $\begin{array}{l}\text { PeqGOLD }{ }^{\mathrm{TM}} \text { Tissue } \\
\text { DNA Mini Kit }\end{array}$ & NucleoSpin ${ }^{\mathrm{TM}}$ Tissue \\
\hline Cat. number & $12334-250$ & 11814770001 & 51306 & $12-3396-02$ & 740952.250 \\
\hline $\begin{array}{l}\text { Number of } \\
\text { preparations }\end{array}$ & 250 & 10 & 250 & 200 & 250 \\
\hline Sample size [mg] & $1-25$ & 400 & 25 & 30 & $1-25$ \\
\hline Elution volume $[\mu \mathrm{L}]$ & 50 & 1000 & $50-200$ & $50-200$ & $60-100$ \\
\hline $\begin{array}{l}\text { Processing time } \\
\text { (hrs:min) }\end{array}$ & 00:15 & 02:30 & $02: 30$ & 03:20 & 03:15 \\
\hline
\end{tabular}

In order to detect inhibitory effects, a real-time PCR assay was incorporated specifically detecting bacteriophage $\lambda$-DNA as described previously (Table 1) [10]. The melting points measured for IS711 and the bacteriophage $\lambda$-DNA target were at approximately $64^{\circ} \mathrm{C}$ and $50^{\circ} \mathrm{C}$, respectively.

Comparison of DNA yield obtained with the kits tested in this study showed significant differences as determined by one-way ANOVA ( $\mathrm{p}<0.05$ ). Kits of QIAGEN and Roche provided the highest amount of DNA (Table 1), Macherey-Nagel and Peqlab products were intermediate whereas MoBio yielded the lowest amount of DNA. We also observed differences in Brucella melitensis DNA content between organs. One-way ANOVA $(\mathrm{p}<0.05)$ showed significant differences of the mean between the amount of DNA in pancreas and the right mammary lymph node of dromedary D1469/06. In animal D1452/06 we found a significantly higher bacterial concentration in the right kidney than in spleen tissue. Inhibition of the PCR and/or insufficient DNA yield was observed with liver, spleen, intestine, lymph node, and spinal cord tissue preparations using the MoBio kit leading to negative results. Preparations of spinal cord and pancreatic tissues extracted using the Roche kit showed inhibition of the internal amplification control and also low DNA yield. For the selection of a DNA extraction method several factors besides the recovery of DNA and the elimination of inhibitory substances have to be considered for practical and economic reasons. Table 2 displays sample volume, elution volume, and processing time for each extraction method. All kits can be handled easily, but the hands-on time ranges from $30 \mathrm{~min}$ to $3 \mathrm{hrs} 30 \mathrm{~min}$ (Table 2).

\section{Discussion and Conclusions}

The diagnosis of brucellosis is challenging as culture of Brucellae and sero-conversion require weeks. Nucleic acid amplification methods might circumvent this diagnostic window, but the very low amount of DNA in tissue samples obviates reliable rapid detection using real-time or conventional PCR techniques. Real-time PCR assays are rapid, specific and have a very low limit of detection, when multi-copy gene targets are used. However, in our experience with clinical samples even highly efficient and sensitive real-time PCR assays frequently fail to detect bacterial DNA due to the extremely low number of bacteria in tissues. For this reason, the aim of this study was to evaluate commercially available DNA extraction kits that should provide high DNA yields and reduce inhibition to improve the results that can be obtained with real-time PCR assays. Based on our experience formalin should be eliminated as much as possible in order to detect even the smallest amounts of target DNA. Therefore, we regarded washing steps and long incubation in saline an indispensable prerequisite. We have decided to test samples from naturally infected animals, because this allowed us to test several organs in parallel and to obtain enough tissue to evaluate a panel of kits. Due to the small amount of bacteria in some samples the DNA yield was sometimes out of the linear range of this real-time PCR assay which reflects the situation under real clinical conditions. Except for one kit (MoBio) all kits yielded enough DNA to regularly provide positive results in real-time PCR assays. The QIAGEN kit provided the highest DNA yield in half of the samples. The Roche kit can be advantageous when relatively large amounts of tissue need to be processed. We have observed differences in DNA yield as high as two orders of magnitude for some samples between the best and the worst DNA extraction kits in this study. This indicates that DNA purification may be more relevant than expected, especially, when the amount of DNA in tissue is very low. Optional RNase steps were performed in none of the assays as the reagents were not supplied with the kits and RNA does not inhibit the PCR reactions. In order to provide identical amounts of DNA eluate the amount of elution buffer was adjusted to $100 \mu \mathrm{l}$ for all kits. It cannot be excluded that these minor changes of 
the purification procedure have adversely influenced the DNA yield of certain kits. In the animals used for this study we observed significant differences in DNA content among different organs. General recommendations regarding favorable tissue samples cannot be given and results obtained from specimens of focal lesions can only be part of a polyphasic diagnostic approach. Further studies in a clinical setting are warranted to assess, whether the use of these DNA preparation methods will actually help to improve the clinical usefulness of realtime PCR assays for the detection of Brucellae in tissue.

\section{Competing interests}

ME was employee of QIAGEN and subsequently of Roche during the study period. The other authors declare that they have no competing interests whatsoever.

\section{Authors' contributions}

HT designed and coordinated the study, drafted the manuscript and participated in performing real-time PCR assays. MK designed the real-time PCR assay and helped to draft the manuscript. ME performed the statistical analyses and participated in study design and drafting of the manuscript. UW isolated and identified Brucella and helped to draft the manuscript. HCS was responsible for DNA isolation, participated in the design of the study and helped to draft the manuscript. SA, ES, and HN participated in the design of the study, the evaluation of the PCR assays and helped to draft the manuscript. All authors read and approved the final manuscript.

\section{Acknowledgements}

We thank G. Echle, R. J. Abi Rached, C. Lodri, and I. Patzwald for excellent technical assistance.

\section{Author Details}

'Friedrich-Loeffler-Institut, Institute of Bacterial Infections and Zoonoses, Naumburgerstrasse 96a, 07743 Jena, Germany, 2Department of Bacteriology, Bundeswehr Institute of Microbiology, Munich, Germany, 32Department of Pathology and Laboratory Medicine, American University of Beirut, Beirut, Lebanon, ${ }^{4}$ Roche Molecular Diagnostics, Rotkreuz, Switzerland, ${ }^{5}$ Central Veterinary Research Laboratory, Dubai, United Arab Emirates, ${ }^{6}$ RWTH Aachen University, Department of Internal Medicine III, Aachen, Germany and ${ }^{7}$ Institute of Medical Microbiology, Friedrich Schiller University of Jena, Jena, Germany

Received: 19 June 2009 Accepted: 20 April 2010

Published: 20 April 2010

\section{References}

1. Al Dahouk S, Tomaso H, Nöckler K, Neubauer H, Frangoulidis D: Laboratory-based diagnosis of brucellosis - a review of the literature. Part I: techniques for direct detection and identification of Brucella spp. Clin Lab 2003, 49:487-505.

2. Al Dahouk S, Nöckler $K$, Scholz HC, Pfeffer M, Neubauer $H$, Tomaso H: Evaluation of genus-specific and species-specific real-time PCR assays for the identification of Brucella spp. Clin Chem Lab Med 2007 45:1464-1470

3. Bricker BJ: PCR as a diagnostic tool for brucellosis. Vet Microbiol 2002 90:435-446

4. Leal-Klevezas DS, Martínez-Vázquez IO, López-Merino A, Martínez-Soriano JP: Single-step PCR for detection of Brucella spp. from blood and milk of infected animals. J Clin Microbiol 1995, 12:3087-3090.

5. O'Leary S, Sheahan M, Sweeney T: Brucella abortus detection by PCR assay in blood, milk and lymph tissue of serologically positive cows. Res Vet Sci 2006, 81:170-176.

6. Zerva L, Bourantas K, Mitka S, Kansouzidou A, Legakis NJ: Serum is the preferred clinical specimen for diagnosis of human brucellosis by PCR. J Clin Microbiol 2001, 39:1661-1664.

7. Queipo-Ortuño MI, Tena F, Colmenero JD, Morata P: Comparison of seven commercial DNA extraction kits for the recovery of Brucella DNA from spiked human serum samples using real-time PCR. Eur J Clin Microbiol Infect Dis 2008, 27:109-114.

8. Wernery U, Kinne J, Joseph M, Johnson B, Nagy P: Where do Brucella organisms hide in serologically positive lactating dromedaries? Proc Int Camel Conf 16-17th February 2007. Bikaner, Rajasthan, INDIA :68-70.

9. Bricker BJ, Halling SM: Differentiation of Brucella abortus bv. 1, 2, and 4 Brucella melitensis, Brucella ovis, and Brucella suis bv. 1 by PCR. J Clin Microbiol 1994, 11:2660-2666.

10. Neubauer H, Meyer H, Prior J, Aleksic S, Hensel A, Splettstoesser W: A combination of different polymerase chain reaction (PCR) assays for the presumptive identification of Yersinia pestis. J Vet Med B 2000, 47:573-580

11. Tomaso H, Reisinger EC, Al Dahouk S, Frangoulidis D, Rakin A, Landt O, Neubauer H: Rapid detection of Yersinia pestis with multiplex real-time PCR assays using fluorescent hybridisation probes. FEMS Immunol Med Microbiol 2003, 38:117-26.

12. Clinical and Laboratory Standards Institute: Evaluation of the linearity of quantitative measurement procedures: a statistical approach approved guideline. CLSI document EP6-A. Wayne, PA: CLS/ 2003.

\section{Pre-publication history}

The pre-publication history for this paper can be accessed here: http://www.biomedcentral.com/1471-2334/10/100/prepub

doi: 10.1186/1471-2334-10-100

Cite this article as: Tomaso et al., Comparison of commercial DNA preparation kits for the detection of Brucellae in tissue using quantitative real-time PCR BMC Infectious Diseases 2010, 10:100

\section{Submit your next manuscript to BioMed Central} and take full advantage of:

- Convenient online submission

- Thorough peer review

- No space constraints or color figure charges

- Immediate publication on acceptance

- Inclusion in PubMed, CAS, Scopus and Google Scholar

- Research which is freely available for redistribution
C Biomed Central 